\title{
TOWARD MIXED-METHODS IMPACT EVALUATION: MAKING STABILIZATION ASSESSMENTS WORK FOR DEVELOPMENT COOPERATION
}

\section{JAN KoEHLER, Kristóf GoSZTONYi, BASIR FEDA, and KeITH CHILD}

Jan Koehler is a Senior Researcher at the Collaborative Research Centre "Governance" of the Free University of Berlin. The corresponding author, he may be reached at jkoehler@zedat.fu-berlin.de. Kristóf Gosztonyi is a Senior Researcher at the Berghof Foundation, Berlin, Germany, and may be reached at K.Gosztonyi@berghof-foundation.org. Basir Feda is a Researcher at the Berghof Foundation, Berlin, Germany, and may be reached at B.Feda@berghof-foundation.org. Keith Child, in Ottawa, Canada, is an independent consultant specializing on impact evaluation and learning. He may be reached at kchild@outlook.com.

\section{Abstract}

We introduce a mixed-methods approach to assess the impact of a complex development program on stability and present a selection of relevant results on stabilization dynamics and possible program-related impacts. The program is implemented by an international nongovernmental organization and combines capacity building with infrastructure development at the district level in North Afghanistan. We develop a working definition of stability and define context-relevant stabilization indicators. We then analyze how various stabilization indicators relate to each other and observe how they change over time. Finally, we analyze how proxies for program activity relate to the stabilization dynamics observed. At this stage, the data analysis is exploratory, and the results are illustrative rather than definite in regard to the success or failure of the stabilization program.

$\mathrm{F}$ ollowing the toppling of the Taliban in 2001, insurgent groups reorganized for a drawn-out campaign to oust foreign troops and topple what they perceived as the Western-supported, puppet government of then-President Hamid Karzai. The insurgency gained strength, and by 2009 warnings mounted that if things did not change the Taliban would overrun the country. The increasingly dire situation led to a shift in strategy from an enemy-centered "war on terror" rationale to a population-centered counterinsurgency strategy (COIN). This shift in strategy was flanked by a United States-led military surge, announced in 2009, and complemented by a civilian surge to strengthen Afghan government structures and to prepare them for taking over responsibility for the country once foreign troops were to be withdrawn in $2014 .^{1}$

Within this context, an international nongovernmental organization launched a wide-ranging program of activities in 2010 in North Afghanistan, intended to help improve overall stability in the region. ${ }^{2}$ This program provides infrastructure financing and associated capacity-building training in the fields of administration, monitoring and quality control, maintenance, environmental and disaster protection, conflict management, gender balance, and institutional development. The initiation and objective of the NGO's stabilization program - henceforth simply referred to as "the program"-fit within the wider international effort to turn the tide in Afghanistan and to support an Afghan state which, with continued, albeit reduced, support from the international community would be able to stand its ground against insurgent forces. In spring 2010, the NGO's evaluation unit teamed up with researchers from Berlin, Germany, to develop a robust longitudinal research strategy to measure the program's impact on stabilization.

This article introduces the impact assessment, discusses its methodology, and presents a selection of relevant results on stabilization dynamics and possible program-related effects. The analysis builds on the impact hypothesis identified in the program's theory of change, introduced in the next section. Based on the impact model of the program, we then define context-relevant stabilization indicators in four fields, namely, security, governance, development, and adaptation. We then analyze how stabilization indicators relate to each other and observe how they change over time. Finally, we define proxies for program activities and analyze how these relate to the stabilization indicators of the four fields of stabilization.

Our data analysis is exploratory. Under the circumstances, research by way of a proper population-based experiment with randomly sampled treatment (or program exposure) and control groups could not be set up. Even as we control for a wide range of factors that we consider causally relevant for the observed stabilization dynamics, we interpret our empirical findings regarding measures of program activities and stabilization dynamics as correlations rather than as causal 
effects. This caveat has to do with the complex and multi-causal nature of stabilization dynamics; a wide range of known as well as potentially unknown factors may affect relevant stabilization indicators that, according to the impact model, should be influenced by program activities. Hence, omitted variable bias could not be ruled out. Furthermore, feedback effects, or even reverse causality, between our proxy variables for program activities and some of the variables measuring stabilization dynamics cannot be statistically excluded and are verified only against qualitative observations and arguments of plausibility. A case in point is the strong positive relation we found between infrastructure implementation and respondents' subjective district-security assessment. Since at least minimal security in terms of site access was a selection criterion for infrastructure development, reverse causality would be likely in this case. Whenever possible we draw on qualitative data to critically assess if a case for partial causation can be made. A follow-up survey is ongoing and, in time, we will revisit the models in light of new quantitative data and updated qualitative information on the target region.

\section{Stabilization program strategy}

To foster district-level stabilization, the NGO's program focuses on infrastructure financing and strengthening the capacity of selected subnational governance institutions to deliver locally adapted development activities and results via transparent procedures. The key governance institution targeted by the program is the District Development Assembly (DDA). DDAs are district-level councils composed of representatives from Cluster Level Development Councils (CLDCs) which, in turn, are composed of representatives from elected Community Development Councils (CDCs). The latter were established as part of a donor-funded National Solidarity Program (NSP), and they fall under the responsibility of the Ministry of Rural Rehabilitation and Development (MRRD). Since their launch in 2003, CDCs have become important village-level governance institutions in many parts of Afghanistan.

The program follows the same approach and implements the same modules in all target districts. As mentioned, it trains DDAs in the fields of administration, monitoring and quality control, maintenance, environmental and disaster protection, conflict management, gender balance, and institutional development. Training should enhance their capacity to competently prioritize the development needs of their district, monitor the implementation of development projects, strengthen cooperation between societal and government administration actors at the district level, and provide governance services in areas not adequately covered by the
In 2010, an international nongovernmental organization introduced a stabilization program in North Afghanistan, tasking researchers with program evaluation. We provide an introduction to the impact assessment, discuss its methodology, and present a selection of relevant results on stabilization dynamics and possible program-related effects.

state (e.g., conflict resolution). This capacity-building component is incentivized by providing block grants and technical expertise for the implementation of infrastructure projects as prioritized by the capacitated DDAs.

The program assumes that by strengthening DDAs in this way-i.e., by financing infrastructure projects and providing capacity-building training to them - stability within the target districts can be increased. These activities are thought to lead to two key outcomes: (1) increasing access to development and (2) making DDA planning more relevant, implementation more effective, and district-level governance more responsive to people's needs. In turn, these outcomes should lead to the overall, aggregate goal of stabilization - securing peace-by establishing reliable governance institutions that promote democracy, equity, justice, and the fair allocation of resources.

\section{Assessment strategy}

How can one assess district-level stabilization dynamics and examine the impact of capacity building and infrastructure provision on those dynamics? First, we capture stabilization dynamics by establishing and analyzing variables adapted to the local context. Second, we adopt proxies for program activities while controlling for potentially confounding factors. Third, through appropriate statistical methods, we test for partial effects of program activity on stabilization, while interpreting the results in light of extensive qualitative knowledge of the target region. In the following sections we explain this approach in detail. ${ }^{3}$

Taking into consideration both the program's own concept of stability and theoretical ideas on the dynamic stability of social order, we arrived at a working definition of stability that comprises four fields. In terms of physical security, stability is defined by low levels of socially unacceptable violence. (Some forms of violence may be socially accepted and therefore are not detrimental to stability.) The program's intended effect on security is explicit, although indirect, in that it intends to add to sustainable improvements of security via more effective and legitimate local governance as well as via more inclusive and fair access to development resources. ${ }^{4}$

Stability is also defined by institutionalized forms of legitimate governance, i.e., well-functioning governance institutions. The more complex society and its segments, the 
more important are the reliable and legitimate regulation of collective tasks, issues, and conflicts. Thus, to foster districtlevel stabilization, improving local development governance is the core building block of the program. Better access to reliable services to solve inter-communal development problems, among other issues, is thought to increase the acceptance of the state and reduce the influence of insurgent groups or the legitimacy of violent resistance.

Social stability is further defined by the ability of various segments of society to materially sustain themselves. Economic reproduction and development is therefore the third defining aspect of stability. The program's capacity building activities in

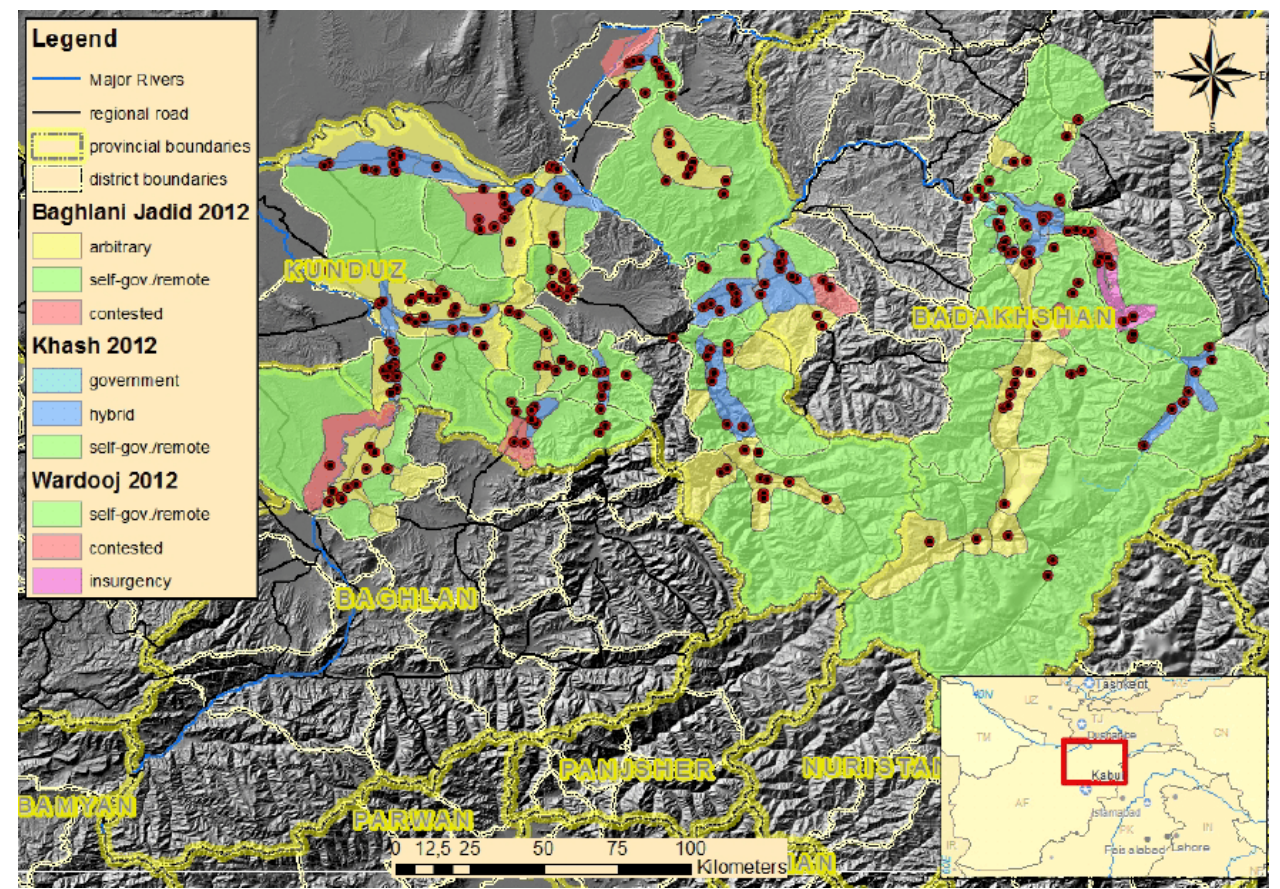

Figure 1: Governance zones in the research area, 2012. Note: The three districts named in the legend show the colors used to represent all six zones. The dots represent villages in which research was conducted.

\section{terms of development governance}

and investments in district-level infrastructure projects hope to have a knock-on effect on economic development, raising the opportunity cost of engaging in destructive and violent life strategies and increasing long-term planning security for households.

Finally, another vital component of social stability is related to adaptive change to modernization, the ability to adapt to changing environments via innovation and development. The program's activities introduce new approaches in a number of respects: development governance, infrastructure maintenance, project management, monitoring, gender mainstreaming, and conflict resolution. These may challenge traditional values and the way things were done in the past. The program's participatory and context-sensitive implementation strategy is thought to mitigate potentially disruptive or destabilizing aspects of these modernizing interventions. At the same time, the inclusive nature of the participatory approach may empower groups that hitherto have been disadvantaged (e.g., villages vs. state administration), once again challenging the adaptive capacity of local society.

To assess the dynamics in these four fields of stability over time, and the program's possible partial impact on them, we opted for a mixed-methods survey approach that combines quantitative data with qualitative research. Survey development was preceded by extensive regional qualitative and quantitative research, which was essential to identifying context-sensitive and locally meaningful indicators for stability (see below). The quantitative survey forms the backbone of the assessment, complemented by comprehensive qualitative research focusing on the same districts and communities. The qualitative research serves two main purposes. We used its results to develop quantifiable indicators which we then integrated into the statistical analysis (e.g., data pertaining to the village economy), and we used the qualitative research to interpret and explain our statistical findings within the local context. ${ }^{5}$

Our quantitative data consists of two successive baseline household (Wave 1) surveys in North-East Afghanistan in 2010 and 2011 with a follow-up (Wave 2) survey conducted in the same villages in 2012 (see Figure 1). The primary sampling unit for the survey is the village represented by the CDC. We interviewed representative samples of randomly selected households proportionate to the number of households within each CDC. We selected 253 out of a total of 2,048 CDCs in 25 target districts, conducting 4,959 interviews in Wave 1 and 5,219 interviews in Wave $2 .^{6}$

In addition to the quantitative survey component, especially trained profile teams collected structured information on the political, economic, social, and demographic situation and history of each target village/CDC. Similar profiles were compiled for CLDCs and districts. Our teams also conducted 
some 250 guideline interviews at the district level. ${ }^{7}$ Furthermore, research supervisors conducted interviews in-field in all target provinces and all survey teams were debriefed in an intensive week-long session.

\section{Developing context-sensitive stabilization indicators ${ }^{8}$ Security}

The research region's security context is influenced most strongly by the presence and conduct of Afghan and foreign security forces, including more or less formalized progovernment militias, on the one hand, and various groups of insurgents, on the other. The most important dynamic for the assessed period relates to the U.S. surge to push insurgents back and create space for the Afghan National Security Forces (ANSF) and the Afghan government to re-establish themselves in the cleared areas. The anti-Taliban offensive was at its peak during the Wave 1 baseline survey in 2010-11. By the time of the follow-up, Wave 2, survey in 2012 significant areas had been taken back from insurgents and the handover of security responsibilities to the ANSF was well under way. ${ }^{9}$

We use four kinds of indicators to depict the fluid security context. First, from the household survey, we built a combined index for household and district-level subjectively perceived security. Second, using Latent Class Analysis, we calculate a number of clustered categorical indicators derived from a question that asks respondents to rate their fear of different armed and violent actors present in the region. Third, we built additional variables from questions on future perspectives on security, on fear of foreign forces (ISAF), and on fear of insurgents (Taliban). And, fourth, we used expert-coded incident counts pertaining to predefined impact areas around the village clusters we assessed..$^{10}$

\section{Governance}

State formation in a society fragmented by decades of civil war is primarily a governance challenge. The Afghan constitution sets up a highly centralized state, with five tiers of governance at the national, provincial, district, municipal, and village levels, and a wide range of actors in Afghanistan affect the political and social regulation of collective tasks and problems. At present, the main grassroots representative structure is the complex of CDCs, CLDCs, and DDAs. ${ }^{11}$

We focus on district and village-level governance. At these levels, the constitutionally mandated, elected representative institutions - District Councils - have not yet been established. Meanwhile, the DDAs, which also form the central target institution of the NGO's program, fill the gap. Patronage networks influence appointments to virtually all subnational administrative positions. As a result, successful local administrators and functionaries need to have good relations with local strongmen as well as political protection from Kabul-based patrons. ${ }^{12}$

The most relevant recent dynamics relate to the unfinished process of subnational governance formation, on the one hand, and the security dynamics described previously, on the other. The relation between the central state and local communities has been a long-standing, problematic issue for the formation of an effective Afghan state. Even as a persistent demand for legitimate state services and interventions exists when local institutions are unable to solve governance problems, the state never fully penetrated society with its institutions, and rural communities have a history of challenging state rule if they considered state intervention illegitimate. To address and solve problems, rural communities rely on their local institutions whenever possible. Hence, the elected development councils with a formal role vis-à-vis the state administration started playing an important role as intermediaries between state and society at village and district-levels. ${ }^{13}$

The changing and patchy security environment affects the physical reach of the state in some districts, especially when insurgents or other armed actors prevent government access. Here, the elected councils (CDCs/shuras) of community representatives play a critical role in facilitating selective state access to areas otherwise inaccessible to government officials. In yet other areas local strongmen (mostly former jihadi commanders) play important roles in governance provision.

Our indicators reflect this fluid and fragmented governance landscape (Figure 1). Based on this patchwork, we built coded governance categories, called governance zones, with different actors providing different services to different recipients and at different levels of quality. For our target districts, we identify six typical and recurring zones that define local governance: (1) governance by government, (2) hybrid governance, (3) arbitrary rule, (4) self-governance, (5) contested governance, and (6) insurgency governance. ${ }^{14}$

Further survey-based indicators focus on the provision of different governance functions by different actors, and on the quality of services provided (e.g., security, administrative or community care, fairness or corruption in dealing with conflicts). We also constructed a 1-10 scaled variable based on who is perceived to be the most powerful person at village and district-levels, with the highest scores for elected or appointed official positions and the lowest scores for informal "men of the gun." Finally, we used additional indicators based on district profiles that assess the level of education and presence-at-work of six predefined leading government officials such as the district governor or the chief of police. 


\section{Economy and development}

According to most of the established development indices, Afghanistan has been and still is one of the poorest countries on earth. One principal goal of development interventions in Afghanistan is poverty relief and improvement of the economic situation of households and communities. This goal connects to the NGO's aforementioned stabilization goals. Agriculture dominates the economic life of rural households in the target region and access to agricultural land is of paramount importance, both for subsistence and cash generation. Trade in agricultural products, livestock, and related goods plays an important role as does open access to inter-communal bazaars. Less important than in the urban centers, although relevant, are wage labor and income opportunities from jobs provided by the government or owing to development activities. ${ }^{15}$

The most important recent events have been the intensification of development initiatives alongside the military surge and COIN strategy beginning in 2010. The German and the U.S. governments increased their spending significantly and put greater focus on rural development as well as on capacity building and training for subnational governance institutions. In terms of the "real" economy, different local opportunities and dynamics play a role. In parts of the research area the illicit drug economy is a dominant economic force while, in other parts, the local economy is strongly influenced by licit and illicit mining. Revenues from cash-generating activities are increasingly invested in construction businesses, particularly in the rapidly growing urban centers. ${ }^{16}$

We relied on survey-based indicators to measure general subjective development exposure and satisfaction with development-induced changes at the village level across different sectors (drinking water, agricultural production, roads, jobs, electricity, medical facilities, and schooling). ${ }^{17}$ Additionally, we use survey questions to assess the material status of respondent households as well as an aggregated indicator reflecting the equality of access to land within the community. Indicators based on village profiles focus on mobility (cars), agricultural mechanization (tractors), and the number of implemented projects per village over a two-year period. Finally, we use district profiles to create an index showing the size of the inter-communal bazaars relative to the estimated district populations.

\section{Modernization and adaptation}

Historically, various domestic and alien powers imposed on Afghan society a top-down attempt at modernization. In the 1920s, Amanullah Khan mimicked Mustafa Kemal Atatürk's state-imposed reform of Turkey. Daud Khan introduced authoritarian republicanism in the 1970s. Replaced by a communist coup, an imposed socialism followed under Soviet occupation. All these attempts at top-down reforms and modernization encountered various levels of social resistance. In contrast, the Taliban enforced their regime with reference to an explicitly anti-modern religious ideology in terms of the social order it promotes. ${ }^{18}$

Society's willingness and ability to adapt is an important variable for its dynamic stability. State formation and the international development intervention after the ousting of the Taliban regime are modernizing challenges for rural Afghan society in particular. Historically, the most sensitive issues have been religion, family, and gender relations. Some of the changes that came with foreign intervention affected these issues ideologically, like the foundational notion of gender equality and human rights (instead of a reference to a universal religious code). Widespread access to public schools for both sexes, and especially the education of girls after reaching puberty, can be economic and value challenges for households, and they loosen the traditional control of parents over their children. Other challenges are more technological, like mobile phones which enable women and teenagers to engage in forms of communication that were unthinkable only a few years ago. For many people, relatively recent access to electricity and passable roads (even in remote areas) are an additional means to new sources of information. ${ }^{19}$

We use survey-based indicators to assess openness, or reservation, toward public school curricula and a composite 1-10 indicator consisting of respondents' evaluation of four value statements regarding girls' and boys' education, off-farm work for women and men, and the impact of public schooling on community norms. We also ask directly if development is a threat to Islamic norms and local values. Regarding access to modern information technology, we ask for the number of bank accounts and mobile phones per household and for the main sources of information accessed by respondents. Indicators derived from qualitatively gathered data are the ratio of public to religious schools per village and the district-level gender ratio of school enrollment.

\section{Stabilization dynamics: Descriptive statistics and Principal Component Analysis}

We first describe the main changes observed in the four fields of stabilization between the baseline (2010-11) and follow-up (2012) surveys. For each field, we then use Principal Component Analysis (PCA) to analyze how the variables relate to each other. Given the high dimensionality of our data, the PCAs build optimal composite indices of the indicators chosen to measure stability per field. This is geared at testing whether the indicators assess similar or different aspects of stability, 
and hence help to possibly reduce the number of dimensions. Indicators from the same field relating more closely to each other should be explained by the same component and be as independent as possible from any other extracted component. The tables that follow show how the indicators load on the different components identified by PCA per field. Whether positive or negative, indicators loading on the same component are statistically closely related to each other. ${ }^{20}$

The key development in the field of physical security is an overall improvement as a result of the military surge and the build-up of the ANSF. This is visible in the average decline of incidents counted per district and within our target CLDCs. The most dramatic change relates, however, to fear perceptions. The number of respondents who were not afraid of any armed actor increased nearly twofold while fear of the Taliban dropped by almost half. Interestingly, average subjective assessments of district and household security remained unchanged but showed strong variation and shifts between districts, coinciding with objective security trends in those districts.

The PCA of the follow-up survey (Table 1) shows that subjective perception of security, general fear, and incidents correlate and pull in the same direction (Comp2). They are unrelated to being afraid of specific groups (i.e., Taliban, ISAF), which are in Comp1. Fear of Taliban, ISAF, and of informal armed groups ("fear some") are fairly undifferentiated: People are either afraid or not afraid of all (Comp1). For Comp2, "fear some" points in the opposite direction: People are less afraid of militias where the other security indicators are worse, indicating that informal security actors are more acceptable where the general security environment is bad. The PCA also indicates that respondents who are unhappy with the COIN-driven security situation in 2012 expect improved security from ISAF's pending withdrawal (Comp3).

The field of governance presents a mixed picture. (As before, we first present a summary of changes between baseline and follow-up; the related PCA, in Table 2, is discussed afterward.) The government administration clearly has gained ground in terms of objective and subjective indicators. Regarding the latter, by the time of the Wave 2 survey, appointed district managers, who are the main representatives of the central government in the districts, were generally perceived as the most powerful actors within a district. The perceived fairness of conflict resolution and the responsiveness of the district administration also improved, albeit marginally. Objective indicators of district administration capacity, presence-at-work, and the level of education of key government officials also visibly changed for
Table 1: Principal Component Analysis for security

$\begin{array}{lcccc}\text { Variable } & \text { Comp1 } & \text { Comp2 } & \text { Comp3 } & \begin{array}{c}\text { Un- } \\ \text { explained }\end{array} \\ \text { Incidents } & & 0.6509 & & 0.3774 \\ \text { Fear ISAF } & 0.4317 & & -0.4119 & 0.2716 \\ \text { Fear Taliban } & 0.4848 & & & 0.1535 \\ \text { Fear all } & 0.3343 & 0.4666 & & 0.3052 \\ \text { Not afraid } & 0.5295 & & & 0.0679 \\ \text { Fear some } & 0.4213 & -0.2466 & & 0.3507 \\ \text { Subj. security } & & 0.4890 & -0.4538 & 0.3298 \\ \text { Outlook 2014 } & & & 0.7597 & 0.2059\end{array}$

Table 2: Principal Component Analysis for governance

$\begin{array}{lcccc}\text { Variable } & \text { Comp1 } & \text { Comp2 } & \text { Comp3 } & \begin{array}{c}\text { Un- } \\ \text { explained }\end{array} \\ \text { Gov. zones } & & & 0.4142 & 0.6574 \\ \text { Pol. security } & 0.2109 & -0.2215 & 0.5383 & 0.1907 \\ \text { Gov. cares } & & & 0.5801 & 0.2698 \\ \text { Inclusiveness } & 0.4078 & & 0.2055 & 0.4241 \\ \text { Social } & 0.3261 & 0.2741 & & 0.5546 \\ \text { cohesion } & & & & 0.2401 \\ \text { Power distr. } & 0.4956 & & & 0.2449 \\ \text { Power village } & 0.5057 & & & 0.3234 \\ \text { Gov. fairness } & & 0.5302 & 0.3059 & 0.3280 \\ \text { DDA fairness } & -0.2436 & 0.4876 & & 0.2558 \\ \text { CDC fairness } & & 0.5540 & & 0.8336 \\ \text { Corruption } & -0.2173 & & & \end{array}$

the better. However, indicators related to the shura-complex (CDCs, CLDCs, and DDAs) worsened: Conflict resolution by the DDAs or CDCs was perceived as less fair than during the baseline survey, the CDCs were felt to be less responsive, and the heads of the (CDC)-shuras were perceived less often to be the most powerful person in the village. In relative terms, however, the CDCs remain among the top governance performers, losing some ground primarily to elders and the ulema (i.e., Islamic scholars and clerics). Village cohesion, 
measured via participation in hashar (communal work), improved between the baseline and follow-up surveys.

The qualitative district assessments help to explain the relative deterioration of the shura-complex. It is linked to the setting up of militias as part of the counter-insurgency campaign between baseline and follow-up. This re-empowered local commanders who, while often perceived as conducive to military aspects of security (i.e., keeping insurgents out of an area), began to meddle in local-level governance provision, negatively affecting its fairness and professionalism. In line with this expectation, the deterioration observed for the shura-complex is limited to those areas where militias were active.

The PCA of the survey data confirms that our normative indicators for legitimate power and fair governance are correlated but in an unexpected negative way: Informal power is linked to more fairness in conflict resolution, official power to less fairness (Comp1). Our analysis of governance zones confirms this finding as zones in which commanders dominate (arbitrary rule) are positively associated with security and fair conflict resolution. This indicates that under current conditions there seems to exist some demand for locally embedded, informal security providers. Other indicators behave as (normatively) expected in the PCA: Higher formalization and more state involvement (governance by government, hybrid governance) correspond to higher levels of attributed police and district administration performance (Comp3). Higher social cohesion goes together with just conflict resolution and lower values for a positive security effect of the police (Comp2), indicating a functioning shura system capable of solving local conflicts in the absence of the state. ${ }^{21}$

Trends in the field of economic reproduction and development are mixed as well. While total project counts dropped, the perceived positive change in the field of development improved, the only exception being the perceived positive contribution of government to development, which decreased. Objective economic indicators also remained unchanged or even improved, such as the size of bazaars and the number of cars per target village/CDC. Lastly, inequality and poverty increased as measured by access to and possession of land.

The PCA (Table 3) produces three components. The first captures development and public service indicators, the second rural and agricultural aspects, and the third individual economic potential. This shows that development, the private sector economy, and rural subsistence agriculture are largely independent of each other. Progress in any one of these sectors does not necessarily mean progress in the other sectors, and development does not automatically influence private business
Table 3: Principal Component Analysis for development

$\begin{array}{lcccc}\text { Variable } & \text { Comp1 } & \text { Comp2 } & \text { Comp3 } & \begin{array}{c}\text { Un- } \\ \text { explained }\end{array} \\ \text { Project count } & 0.2062 & & -0.2452 & 0.7901 \\ \text { Positive dev. } & 0.5504 & & & 0.1535 \\ \text { Dev.org.cont. } & 0.4402 & & & 0.4353 \\ \text { Gov. contrib. } & 0.4388 & & 0.5069 & 0.5460 \\ \text { Mat. } & & & 0.4644 & 0.6430 \\ \text { wellbeing } & & & & \\ \text { Car index } & & & & \\ \text { Bazaar index } & & -0.2695 & 0.3867 & 0.5989 \\ \text { Land equality } & & 0.6460 & & 0.3311 \\ \text { Landless/pov. } & & 0.6366 & & 0.3277 \\ \text { Tractor index } & & 0.2509 & 0.5316 & 0.5522 \\ \text { Dev. exposure } & 0.5061 & & & 0.2940\end{array}$

Table 4: Principal Component Analysis for adaptation

\begin{tabular}{|c|c|c|c|c|}
\hline Variable & Compl & Comp 2 & Comp3 & $\begin{array}{c}\text { Un- } \\
\text { explained }\end{array}$ \\
\hline $\begin{array}{l}\text { Modern } \\
\text { values }\end{array}$ & 0.4021 & 0.2412 & 0.2180 & 0.4788 \\
\hline Modern media & & 0.7345 & -0.2464 & 0.1831 \\
\hline Girl schooling & 0.5698 & & & 0.3979 \\
\hline State employ. & & -0.2848 & & 0.8605 \\
\hline Value threat & 0.3806 & 0.3490 & 0.2971 & 0.3469 \\
\hline $\begin{array}{l}\text { Madrassa } \\
\text { ratio }\end{array}$ & & 0.3396 & 0.3584 & 0.6815 \\
\hline $\begin{array}{l}\text { Dissat. } \\
\text { curricula }\end{array}$ & & & 0.7950 & 0.1527 \\
\hline Cell phones & -0.5841 & 0.2102 & & 0.3306 \\
\hline
\end{tabular}

or the dominant rural subsistence economy in a positive way.

Contradictory trends characterize the field of adaptive change as well. Girls' school enrollment increased further even as the number of madrassas (religious schools), an indicator of conservative values, increased as well. After years of growing openness toward a more liberal interpretation of gender rights, 
we see a marked shift toward conservative attitudes during the follow-up survey (e.g., the rejection of state school curricula and girls' education, or the perception that development threatens local values). Turning to the technological aspects of modernization, between the baseline and follow-up surveys, we note an increased use of modern media to gain information as well as more bank accounts and more cell phones.

The PCA (Table 4) shows negative correlations (Comp1 and Comp3) between indicators of technological (mobile phones, modern media access) and social (values, education) modernization. The technological and social clusters stand for different kinds of modernization and adaptation and seem in at least partial contradiction to each other. Access to modern media and sources of communication (cell phones are increasingly used even in the countryside) may connect selectively to larger and dominant normative discourses about perceived contradictions between the West and the Islamic world and may inform local communities about divisive global incidents such as the burning of the Koran. We found a further indication for a connection between increased scepticism toward modern values and a wider discourse on threats to Islamic societies by analyzing guideline interviews conducted in all village clusters covered by the survey. There was almost no evidence in the interviews for concrete local experiences to explain the value threat perceptions but a far greater number of explanations that linked threat perceptions to the global controversies.

\section{The program's effects on stabilization}

Thus far we have identified the main theory underpinning the program activities, arrived at a working definition of stability, defined context-specific indicators, and used them to assess relevant stabilization dynamics. In this section we describe a testable impact model of the program's activities. This requires specifying activity-related independent variables (IVs), the dependent stabilization variables (DVs), and relevant control variables that could affect both program activity and stabilization. All variables, except for the activity-related IVs and some additional control variables are built from the stabilization indicators introduced earlier on. To assess the relation between program activity and stabilization dynamics, we opted for Ordinary Least Squares (OLS) regression analysis. To build the statistical models, we defined four independent variables that measure program activity, chose twelve meaningful dependent variables from the four fields of stabilization, and controlled for 18 other variables. ${ }^{22}$

The dependent variables are derived from the four fields of stabilization: physical security, governance institutions, economic development, and adaptive change (modernization).
We enter the primary variables of interest in interaction with district dummies. The decision to include district dummies was informed by extensive qualitative research of the target region which revealed strong cross-district variations in terms of security, governance, economic potential, and adaptive capacity. In addition, the centrality of the DDA as the key district-level institution targeted by the program puts differences between districts into focus. Descriptive statistics derived from the two survey waves also show significant variation on a number of variables between and within districts. From a statistical point of view, this approach ensures that the clustered/nested structure of the data collected via a complex sampling method is taken into account. ${ }^{23}$

While we defined a total of twelve DVs relating to the four fields of stabilization and four IVs for program activities, for reasons of space constraints we present and discuss in this article results from a subset of only three dependent and two independent variables in the fields of governance and adaption. (Full results are available from the authors upon request.) The DVs are Wolliswoli (district administration) care, social cohesion, and value threat - elaborated upon shortly — and the IVs are project visibility and DDA visibility, also elaborated upon shortly. In what follows, we test the impact hypothesis upon which program is based.

Within the field of governance we discuss two DVs: Wolliswoli care (our proxy for output legitimacy of the state administration at district level) and hashar obligations (our proxy for social cohesion). We hypothesize that the program improves legitimacy and effectiveness of both district and community-level governance via capacity building, the introduction and application of procedures, on-the-job training, and by connecting communities with district-level institutions. ${ }^{24}$ Regarding the capacity for adaptive change we investigate a variable called development as value threat. We hypothesize that the program improves openness and competence to adapt to new, modern technologies, information, and organizational reforms. This is achieved via participatory approaches to development in which the DDA is an increasingly legitimate and competent two-way transmission belt for development initiatives between the state and NGOs, on the one hand, and communities, on the other. ${ }^{25}$

To measure program activities we defined four primary independent variables (IVs) based on program visibility and an assessment of the utility of program activities for the district. The respondents were asked if they have heard about the DDA and the program's district-specific infrastructure projects as well as what they think about their usefulness for the district. These variables capture the program's intent to improve the visibility and perceived performance of its principal partner 
and of the specific infrastructure projects this partner facilitates via block grants. We argue that awareness and perception are more meaningful measurements of the program's intended stabilization impact than material outcome indicators alone: At the heart of the impact model lies the improvement of trust and legitimacy through better local governance and this, to a large extent, is a subjective perception. On a technical note, the block grants received by the DDAs are of similar size in all program districts, and the procedures of project selection deciding about the use of the block grants are similar as well. There is thus no variance on this factor.

In the following section, we restrict ourselves to reporting results related to the visibility IVs only, i.e., project visibility and visibility of the DDA. In addition to the mentioned control variables, we also control for (1) all Wave 1 baseline scores for DVs, where applicable, (2) objective project count per village, and (3) subjective development exposure per village as we anticipate that the relation between the program activity-related variables and the dependent variables measuring stability is affected by the baseline score of an indicator (e.g., subjective fear levels) or the exposure of respondents to other development projects. ${ }^{26}$

The reported marginal effects relate to project visibility and DDA visibility exactly as per model specification. As argued, since capturing the net effect of the program on stability is the main challenge of an impact assessment, we control for all possible covariates that could, in theory, affect stability, including, among others, general village-level development exposure (both subjective and objective). However, decoupling program activity-related IVs from subjective development exposure (which captures all other development initiatives) and entering them both in the same model could raise misspecification concerns because one might assume that the two are highly correlated. This is, however, not the case as (1) they refer to different levels of societal organization (village vs. district) and are different in their degree of strategic implementation (ad hoc vs. long-term), and (2) multicollinearity tests conducted for each regression model and correlations among the variables concerned do not point to these being collinear. After adding district interactions and control variables we find the expected relations based on our theoretical framework. Omitted variable bias cannot be excluded, but the interaction terms introduced in the models control for district-specific contextual effects.

\section{Results of the regression analysis}

The first observation is that the level of aggregation matters: Statistical significance, strength, and direction of effects vary across districts in almost all models related to the four fields of

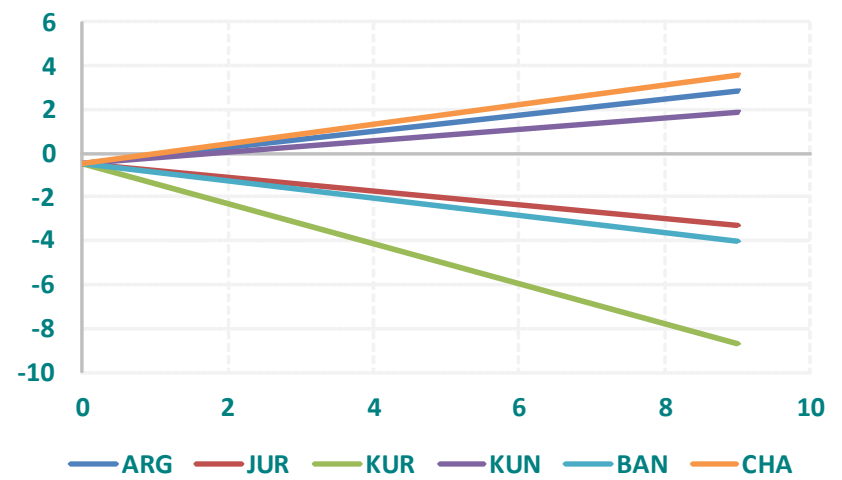

Figure 2: District partial effects: Project visibility on value threat. Note: Positive slope indicates increasing value threat. Districts: ARG: Arghanj Khaw; JUR: Jurm; KUR: Kuran wa Munjan; KUN: Kunduz; BAN: Bangi; CHA: Chal.

stabilization (for an example, see Figure 2). We believe this heterogeneity of findings is caused by the high degree of fragmentation of the governance landscape - typical for fragile and conflict-affected states - and we consider this to be a key finding of the assessment. In the following, we report only on the statistically significant results (see Table A1) associated with the varying number of districts in fields of stabilization, governance and adaptation. ${ }^{27}$

\section{Governance effects}

In the majority of districts program activities correlate significantly and positively with the indicator we use to estimate the perceived legitimacy of the district administration. Specifically, on average, project visibility in 11 out of the 25 districts is associated with an increase in the perception of a caring district administration (Table A1, Col. 1). Similarly, DDA visibility is associated with an increase in the perception of a caring district administration in 9 out of 25 districts and a decrease in one (Table A1, Col. 2). This is the strongest indication we have in our regression analyses that program activities are related to the legitimacy of the district-level state administration. Positive effects of development efforts on the legitimacy of the state have been observed before; here we have, however, a strong indication that a specific program has such effects even after controlling for other, and sometimes similar development, efforts. ${ }^{28}$

Assessing the relation between infrastructure financing and capacity-building activities on the one hand, and social cohesion as measured by hashar (communal work) compliance on the other, we find that, on average, project visibility is associated with an increase in compliance rates in seven districts and associated with a decrease in six others (Table A1, Col. 3). In contrast, the DDA visibility variable is associated 
with an increase in hashar compliance rates in one district and associated with a decrease in seven other districts (Table A1, Col. 4).

It would appear that one cannot discern a straightforward trend: The relation between the primary IVs and DVs, as derived through the interaction terms, seems to indicate statistically significant positive but also negative associations, reflecting the heterogeneity of effects across districts. The question of whether the program affects pre-existing levels of social cohesion in a positive way or whether it can take a toll on existing functional societal institutions remains an important concern for understanding and controlling possible side effects of program interventions.

There is likely no direct causal link between the visibility of the program's infrastructure projects and social cohesion. It is also not a central aim of the program's infrastructure component to increase social cohesion. This impact is, however, more relevant for the capacity-building component of the DDAs since they are directly involved in the organization of inter-communal hashar, our proxy for social cohesion. As noted, DDA visibility seems to be associated with lower rates of hashar compliance in seven of the eight districts for which we have statistically significant results. It is likely that this result relates to different levels of organization: We observe that DDAs most active in hashar organization do so in a more formal, administrative way to tackle district-level problems (e.g., reacting to natural disasters or emergencies); our proxy indicator refers, however, to the more customary village-level hashar activities. Hence, less local willingness to participate in community-level hashar could be a state formation effect. This effect is likely absent in the heavily insurgency-affected Dashti Archi district, the only district for which there is a positive relationship between DDA visibility and hashar compliance.

\section{Adaptive change}

In twelve districts, a relatively clear connection emerges between the two program activity-related variables-project and DDA visibility, respectively - and the perception of threats to local norms and Islamic values as a consequence of general international development work. However, the direction of these relations is not the same for all districts. Project visibility is, on average, associated with an increase in the level of perceived threat in three districts and with a decrease in another three (Table A2, Col. 1). In contrast, DDA visibility is, on average, associated with a decrease in the level of perceived threat in only one district and with an inverse relation in six others (Table A2, Col. 2). The different effects cluster with provinces: We note a negative relation for districts in Kunduz Province, in which the insurgency is strongest, but a positive relation for districts in Badakhshan which, until 2011, was least affected by the Taliban insurgency.

We only have tentative explanations for these findings. It is possible that DDAs on some occasions come to represent and advocate for modernization within village communities. Based on the results of our qualitative research into the issue of value threat, we find it more likely, however, that the DDA and value threat variables both correlate with an insufficiently controlled for third variable, possibly related to the exposure to specific propaganda (the concentration of negative results in the province most affected by the insurgency points into this direction).

\section{Tentative lessons}

The international NGO whose program we assess attempts to provide an enabling environment for stability. It does so through the provision of community-prioritized development infrastructure meant to improve access to services and subnational governance. At this early stage of project implementation and research into potential long-term effects, it is not yet possible to provide a definite answer as to whether the program has been successful in achieving its intended positive impact. From the observed relations between program activity and stabilization indicators we can, however, draw some tentative conclusions.

In regard to governance, the results on output legitimacy are robust, convincing, and relevant, especially at the district level where Afghans meet, demand, and challenge their state. The partly negative effect on local social cohesion, however, needs to be taken seriously and should inform future modes of program delivery. That a development program focused on the extension of governance services can simultaneously weaken social cohesion and traditional community institutions should not come as a particular shock - state formation may, for example, strengthen the Ministry of Public Works instead of hashar, or DDAs and CDCs instead of traditional shuras. However, in the Afghan context, local self-help and self-organization will be vital for a long time to come. Hence, weakening traditional institutions and increasing everyday exposure to (potentially corrupt) officialdom could pose a serious problem and needs to be understood better.

Regarding adaptive change, our study highlights how important are communication and soft skills, even when projects are implemented through representatives of local community institutions like the DDA, CLDC, or CDC. However, regional effects (e.g., negative results clustering in insurgency-affected Kunduz) also indicate that there may be a stronger ideological force at play that can be influenced only marginally by development work. 
Finally, we emphasize that the strong showing of district effects on the observed relations underline how important a differentiated, local needs and capacities-driven approach is for the success of a program like the NGO's discussed here. In this case, a one-size-fits-all approach does not yield the best results.

\section{Notes}

At different stages, Kristin Bergmann-Warnecke (baseline), Alicia D. Cooperman, Jan R. Böhnke, and Johannes Schult (follow-up) supported us technically for data processing, OLS regression, and advice on statistical methods. We thank them for their work. All remaining errors are ours.

1. Overrun the country: McChrystal (2009a); Woodward (2011). Change to COIN strategy: McChrystal (2009b).

2. The specific organization(s) and donor(s) involved are not named in this article as they are of no concern for the arguments presented here.

3. For details, see Koehler, et al. (2011); Böhnke, et al. (2014).

4. Theoretical ideas: Elwert (2002); Elias (1983).

5. Partial or net impacts are the specific share in impact that can be attributed to program activities. Survey and qualitative data collection took place in cooperation with our Afghan partner organization, AHRRAO, under the supervision of the authors.

6. For details on the multi-stage sampling strategy and indicator development, see Koehler, et al. (2011).

7. Guideline interviews are semi-structured interviews that follow a pre-defined list of guiding questions. In difference to surveys the form of the interview is an open conversation or discussion.

8. Details with full technical explanations of the indicators are available upon request.

9. Push insurgents back: Giustozzi and Reuter (2011). Taken back: NATO (2013).

10. Latent Class Analysis: Böhnke, et al. (2013, p. 29). Expertcoded: Koehler, et al. (2011, p. 14).

11. Constitution: Islamic Republic of Afghanistan (2010). Five tiers of governance: IDLG/MRRD (2013).

12. District Councils not yet established: AREU (2011). Patronage networks: Koehler and Gosztonyi (2011).

13. Demand for state services: Koehler and Gosztonyi (2011). History of challenging state rule: Rubin (2002). Reliance on local institutions: Barfield (2010).

14. On governance zones, see Koehler (2012).

15. Development indices: UNDP (2013).

16. U.S. and German governments: LaFranchi (2011); BMZ (2010).
17. To be clear, here we measure general exposure and satisfaction, not NGO-specific; with the NGO's stabilization program, we then ask for attributed utility (negative, neutral, positive) for the district.

18. Top-down: Barfield (2010). Resistence: Rubin (2002). Taliban religious ideology: Giustozzi (2007; (Nojumi 2008).

19. Universal religious code: See Suhrke (2012, pp. 203-211).

20. High dimensionality of data: Different aspects of security, governance, development, and adaptation each are accounted for with a variety of indicators. Optimal composite indices: Optimality is defined by weighing all indicators in the analysis in such a way that most of the variance is explained. PCA per field of stabilization: Only statistically significant loadings are shown; indicators are scaled (1-10) and directed, with higher numbers indicating higher stabilization scores.

21. Arbitrary rule: See Koehler, et al. (2011).

22. In each field of stabilization, Model 5 constitutes our preferred specification - with the largest number of controlsbased on the impact hypothesis identified in the program's theory of change and best-fit statistics as measured by Rsquared and RMSE. Four alternative specifications include fewer controls.

23. Interaction with district dummies: We introduce interaction terms into the models to account for heterogeneity of effects in relation to each district rather than the aggregated effect of the primary independent variables across all districts as the central units of analysis.

24. Wolliswoli care: A survey question asks respondents whether they believe that the local district administration (Wolliswoli) takes care of community needs. The question is a five category Likert-scale variable ranging from "never" to "always." Hashar obligations: A scale variable ranging from "most people not interested" to "most people interested."

25. Development as value threat: A survey-based composite indicator representing average levels of agreement with four value statements regarding girls' and boys' education, off-farm work for women and men, and the impact of public schooling on community norms.

26. Project visibility: A survey question asks respondents whether they have a heard of a program project, chosen from a list of projects implemented and completed at the district of the respondent at the time of survey. The variable accounts for a program project visibility dummy coded as one for "heard of the project" by the respondent. Visibility of the DDA: Surveybased dummy variable asking respondents whether they have heard of the DDA. Visibility of DDA is an indication of the institution being active.

27. High degree of fragmentation: As mentioned, program implementation is similar across the districts and an additional variable assessing the quality of the infrastructure projects in the eyes of the respondents produced nearly invariant positive results $(99 \%$ attributing a positive effect to the projects they knew of). Hence, we do not believe that differences in 
implementation account for the observed district effects, and we are confident that project visibility is an adequate proxy for program exposure. Statistically significant results: Table A1 includes only results associated with the interactions extracted from the fully specified model (Model 5). The full set of tables is available from the authors upon request.

28. Observed before: Böhnke, Koehler, and Zürcher (2010); Beath, Christia, and Enikolopov (2012).

\section{References}

AREU. 2011. "District Councils. The Missing Middle of Local Governance." Proceedings from an AREU Roundtable Discussion. 27 June 2011 (July 2011). Kabul: AREU.

Barfield, T.J. 2010. Afghanistan: A Cultural and Political History. Princeton, NJ: Princeton University Press. http://dx.doi.org/10.1515/9781400834532

Beath, A., F. Christia, and R. Enikolopov. 2012. "Winning Hearts and Minds through Development? Evidence from a Field Experiment in Afghanistan. Policy Research Working Paper. Washington, D.C.: The World Bank.

BMZ. 2010. "Bundesentwicklungsminister Dirk Niebel: Entwicklungsoffensive in Afghanistan," in Bundesministerium für wirtschaftliche Zusammenarbeit und Entwicklung. 5 May 2010. http://www.bmz.de/de/ presse/aktuelleMeldungen/2010/mai/20100505_ afghanistan/.

Böhnke, J., J. Koehler, and C. Zürcher. 2014. "Assessing the Impact of Development Cooperation in North East Afghanistan 2005-2009: A Repeated Mixed-Method Survey," pp. 105-129 in B. Bull, M. Kennedy-Chouane, and O. Winkler-Andersen, eds. Evaluations in Situations of Conflict and Fragility. London: Routledge.

Böhnke, J., J. Koehler, and C. Zürcher. 2013. "Assessing the Impact of Development Cooperation in North East Afghanistan: Approaches and Methods." SFB Working Papers 43. Berlin: Sonderforschungsbereich 700 "Governance in Räumen begrenzter Staatlichkeit."

Böhnke, J., J. Koehler, and C. Zürcher. 2010. "Assessing the Impact of Development Cooperation in North East Afghanistan 2005-2009." Bonn, Germany: Bundesministerium für Entwicklung und Wirtschaftliche Zusammenarbeit. http://www.oecd.org/countries/ afghanistan/46785983.pdf.

Elias, N. 1983. "Über den Rückzug der Soziologen auf die Gegenwart." Kölner Zeitschrift für Soziologie. Vol. 35, No. 1, pp. 29-40. http://dx.doi.org/10.1007/978-3-322-83504-8_104

Elwert, G. 2002. "Conflict: Anthropological Aspects," pp. 2542-2547 in N.J. Smelser and P.B. Baltes, eds. International Encyclopedia of the Social and Behavioral Science. Amsterdam: Elsevier.

Giustozzi, A. 2007. Koran, Kalashnikov, and Laptop: The Neo-Taliban Insurgency in Afghanistan. New York: Columbia University Press.

Giustozzi, A. and C. Reuter. 2011. "The Insurgents of the Afghan North.” AAN Thematic Report 04/2011. Afghan
Analyst Network. http://aan-afghanistan.com/index. asp?id=1679.

IDLG/MRRD. 2013. "Policy for Improving Governance and Development in Districts and Villages. Kabul: Independent Directorate of Local Governance, Ministry of Rural Rehabilitation and Development.

Islamic Republic of Afghanistan. 2010. "Sub-national Governance Policy." Kabul: Islamic Republic of Afghanistan. http://jawzjan.gov.af/Content/Media/ Documents/SNGP-English-Afghanistan 307201192625245553325325.pdf.

Koehler, J., K. Gosztonyi, and J. Böhnke. 2011. "Conflict and Stability in Afghanistan. Methodological Approaches." Violence, Drugs and Governance: Mexican Security in Comparative Perspective. Stanford University, 4 October 2011. http://cddrl.stanford.edu/events/6716.

Koehler, J. and K. Gosztonyi. 2011. "Sub-District Governance. Social Engineering and Local Governance in North-East Afghanistan," pp. 39-64 in Ml Schaper, ed. Good Enough Governance. Wie kommt der Südsudan zu tragfähiger Staatlichkeit und funktionierender Verwaltung? Loccum, Germany: Format Publishing.

Koehler, J. 2012. "Social Order Within and Beyond the Shadow of Hierarchy. Governance Patterns in Afghanistan.” SFB-Governance Working Papers Series 33. Berlin, Research Centre (SFB) 700.

LaFranchi, H. 2011. "In Afghanistan War, US Civilian Surge Peaks as Pentagon Begins Pullback." The Christian Science Monitor. 23 June 2011. http://www.csmonitor.com/USA/ Foreign-Policy/2011/0623/In-Afghanistan-war-UScivilian-surge-peaks-as-Pentagon-begins-pullback.

McChrystal, S. 2009a. "Commander's Initial Assessment (unclassified with removal of enclosure)." Kabul: Headquarters International Security Assistance Force.

McChrystal, S. 2009b. "Tactical Directive: Unclassified." Kabul: NATO, ISAF Headquarters.

NATO. 2013. "Inteqal: Transition to Afghan Lead." http://www.nato.int/cps/en/natolive/topics_87183.htm.

Nojumi, N. 2008. "The Rise and Fall of the Taliban," pp. 90117 in R.D. Crews and A. Tarzi, eds. The Taliban and the Crisis of Afghanistan. Cambridge, MA: Harvard University Press.

Rubin, B.R. 2002. The Fragmentation of Afghanistan: State Formation and Collapse in the International System. New Haven, CT: Yale University Press.

Suhrke, A. 2012. When More Is Less: The International Project in Afghanistan. New York: Columbia University Press.

UNDP. 2013. Human Development Report 2013. (Explanatory note on 2013 HDR composite indices. Afghanistan.) http://hdr.undp.org/sites/default/files/Country-Profiles/A FG.pdf.

Woodward, B. 2011. Obama's Wars. New York: Simon \& Schuster. 


\section{Appendix}

Table A1: Marginal district effects (governance)

\begin{tabular}{|c|c|c|c|c|}
\hline Variable & (1) & (2) & (3) & (4) \\
\hline BAD arg & $1.211 * * *(0.361)$ & $0.413(0.348)$ & $0.021(0.139)$ & $0.0857(.075)$ \\
\hline BAD_bah & $0.852 *(0.356)$ & $0.474 * *(0.168)$ & $-0.413 *(0.207)$ & $-0.225^{*}(0.089)$ \\
\hline BAD_jr & $0.237(0.239)$ & $0.328(0.284)$ & $-0.130(0.167)$ & $-0.119(0.104)$ \\
\hline BAD_khas & $1.040 *(0.433)$ & $0.462 * *(0.139)$ & $-0.091(0.140)$ & $0.143(0.168)$ \\
\hline $\mathrm{BAD}^{-}$kis & $0.642 *(0.279)$ & $0.027(0.222)$ & $0.329(0.220)$ & $0.180(0.147)$ \\
\hline BAD_kur & $1.642 * * *(0.236)$ & $0.809(0.436)$ & $-0.499 * * *(0.107)$ & $0.026(0.189)$ \\
\hline BAD_war & $0()$. & $0.149(0.132)$ & $0()$. & $-0.113(0.195)$ \\
\hline $\mathrm{BAD}^{-}$yam & $0.990(0.588)$ & $0.619 *(0.279)$ & $-0.594 * *(0.205)$ & $-0.040(0.127)$ \\
\hline BAD_zeb & $1.443 *(0.678)$ & $-0.118(0.250)$ & $-0.463 * * *(0.136)$ & $-0.038(0.115)$ \\
\hline BAD_bj & $-0.312(0.265)$ & $0.068(0.202)$ & $-0.530(0.303)$ & $-0.370 * *(0.127)$ \\
\hline KUN_ali & $0.323(0.446)$ & $1.001 * * *(0.143)$ & $0.188(0.260)$ & $-0.436 * * *(0.127$ \\
\hline KUN_das & $0.141(0.621)$ & $0.649 * *(0.237)$ & $0.874 *(0.371)$ & $0.752 * * *(0.174)$ \\
\hline KUN ima & $1.401 * * *(0.306)$ & $1.771 * * *(0.223)$ & $-0.324 *(0.162)$ & $-0.641 * * *(0.100)$ \\
\hline KUN_kha & $-0.213(0.537)$ & $1.079 * * *(0.256)$ & $0.106(0.302)$ & $0.142(0.219)$ \\
\hline KUN_kun & $0.294(0.731)$ & $2.125 * * *(0.225)$ & $-0.801 *(0.327)$ & $-0.904 * * *(0.142$ \\
\hline TAK_bah & $1.442 * * *(0.272)$ & $0.072(0.240)$ & $0.510 * *(0.164)$ & $0.024(0.102)$ \\
\hline TAK ban & $1.501 * * *(0.319)$ & $-0.213(0.171)$ & $0.624 * * *(0.099)$ & $-0.035(0.062)$ \\
\hline TAK_cha & $-0.547(0.298)$ & $0.265(0.209)$ & $0.769 *(0.342)$ & $-0.387 * * *(0.062$ \\
\hline TAK_esh & $0.363(0.252)$ & $0.002(0.101)$ & $0.669 * * *(0.138)$ & $0.084(0.076)$ \\
\hline TAK_far & $0.552 * * *(0.097)$ & $0.463 * *(0.165)$ & $-0.050(0.315)$ & $-0.368 * * *(0.098$ \\
\hline TAK kal & $0.068(0.184)$ & $-0.112(0.140)$ & $0.490 *(0.193)$ & $0.041(0.052)$ \\
\hline TAK_kho & $0.989 * * *(0.207)$ & $0.168(0.160)$ & $0.180(0.129)$ & $0.165(0.085)$ \\
\hline TAK rus & $-0.205(0.140)$ & $0.055(0.145)$ & $0.290 * *(0.107)$ & $0.107(0.109)$ \\
\hline TAK wars & $0.640(0.430)$ & $-0.523 *(0.221)$ & $0.220(0.177)$ & $-0.042(0.098)$ \\
\hline TAK yq & $0.388(0.312)$ & $0.052(0.142)$ & $0.166(0.156)$ & $-0.149(0.077)$ \\
\hline
\end{tabular}

Notes: Coefficients, followed by standard errors in parentheses. $* * * \mathrm{p}<0.01 ; * * \mathrm{p}<0.05 ; * \mathrm{p}<0.10$.

Col. (1): Marginal district effects of project visibility and Wolliswoli care: Marginal effects of projvis on q28_31_wolliswoli_rec, by district.

Col. (2): Marginal district effects of DDA visibility and Wolliswoli care: Marginal effects of DDAvis on q28 31 wolliswoli rec, by district.

Col. (3) Marginal district effects of project visibility and social cohesion: Marginal effects of projvis on q19_hashar, by district.

Col. (4) Marginal district effects of DDA visibility and social cohesion: Marginal effects of projvis on q19 hashar, by district.

In all cases, marginal effects are derived from OLS models with clustered standard errors at the CDC level to reflect similarity of preferences within a CDC. These marginal effects are from model (5) with all controls included. If the district coefficient $=0$ and $\mathrm{SE}=($.$) , then this district was omitted because it was$ too similar to another independent variable after including all control variables. 
Table A2: Marginal district effects (adaptive change)

Variable

BAD_arg

BAD bah

BAD_jr

BAD khas

BAD_kis

BAD kur

BAD_war

BAD yam

BAD zeb

$\mathrm{BAD}^{-} \mathrm{bj}$

KUN ali

KUN das

KUN ima

KUN kha

KUN kun

TAK bah

TAK_ban

TAK_cha

TAK esh

TAK_far

TAK kal

TAK_kho

TAK rus

TAK wars

TAK_yq
(1)

$$
\begin{gathered}
0.363 * *(0.131) \\
-0.129(0.076) \\
-0.315 *(0.115) \\
0.047(0.071) \\
-0.028(0.036) \\
-0.919 * * *(0.060) \\
0(.) \\
0.0004(0.089) \\
0.270(0.309) \\
0.028(0.068) \\
\\
0.016(0.091) \\
0.193(0.149) \\
0.064(0.083) \\
-0.098(0.101) \\
0.256 *(0.118) \\
0.152(0.136) \\
-0.400 * *(0.137) \\
0.452 * *(0.172) \\
0.181(0.136) \\
0.177(0.306) \\
0.053(0.116) \\
0.038(0.100) \\
-0.013(0.031) \\
-0.133(0.110) \\
0.003(0.138)
\end{gathered}
$$

$$
\begin{gathered}
0.226^{*}(0.101) \\
-0.062(0.042) \\
0.008(0.067) \\
-0.060(0.073) \\
-0.066(0.043) \\
-0.010(0.072) \\
-0.295(0.327) \\
0.025(0.052) \\
0.047(0.172) \\
0.125 * *(0.038) \\
\\
0.101(0.061) \\
0.048(0.051) \\
0.127 * *(0.038) \\
0.181 *(0.079) \\
0.113(0.075) \\
\\
-0.178^{*}(0.071) \\
-0.114(0.064) \\
-0.029(0.067) \\
0.027(0.053) \\
0.168(0.250) \\
-0.047(0.047) \\
-0.020(0.070) \\
0.034(0.043) \\
0.139^{*}(0.068) \\
0.221 *(0.090)
\end{gathered}
$$

Notes: Coefficients, followed by standard errors in parentheses. ${ }^{* * *}$ $\mathrm{p}<0.01 ; * * \mathrm{p}<0.05 ; * \mathrm{p}<0.10$.

Col. (1): Marginal district effects of project visibility and foreign development aid as value threat: Marginal effects of projvis on q32fordevthreat, by district.

Col. (2): Marginal district effects of DDA visibility and foreign development aid as value threat: Marginal effects of DDAvis on q32fordevthreat, by district.

In both cases, marginal effects are derived from OLS models with clustered standard errors at the $\mathrm{CDC}$ level to reflect similarity of preferences within a CDC. These marginal effects are from model (5) with all controls included. If the district coefficient $=0$ and $\mathrm{SE}=($.$) , then this district was$ omitted because it was too similar to another independent variable after including all control variables. 